\title{
Ground motion and rupture process of the 2003 Tokachi-oki earthquake obtained from strong motion data of K-NET and KiK-net
}

\author{
Ryou Honda ${ }^{1}$, Shin Aoi $^{1}$, Nobuyuki Morikawa ${ }^{1}$, Haruko Sekiguchi ${ }^{2}$, Takashi Kunugi ${ }^{1}$ and Hiroyuki Fujiwara ${ }^{1}$ \\ ${ }^{1}$ National Research Institute for Earth Science and Disaster Prevention \\ ${ }^{2}$ National Institute of Advanced Industrial Science and Technology
}

(Received December 1, 2003; Revised March 5, 2004; Accepted March 9, 2004)

\begin{abstract}
A great earthquake, named the 2003 Tokachi-oki earthquake, occurred in the southern Kuril subduction zone on 26th September 2003, 4:50 JST $\left(41.7797^{\circ} \mathrm{N}, 144.0795^{\circ} \mathrm{E}, 42 \mathrm{~km}\right.$ depth; Japan Meteorological Agency). Its ground motion was recoreded at 655 stations of the nationwide strong motion networks, K-NET and KiK-net. A maximum peak ground acceleration of $988 \mathrm{~cm} / \mathrm{s}^{2}$ (gal) was observed at station HKD100 and amplitudes greater than 200 $\mathrm{cm} / \mathrm{s}^{2}$ were observed over a wide area of eastern Hokkaido. We used a multi-line linear waveform inversion method to estimate the rupture process from the strong motion data of supplied by 15 stations. We assumed a fault plane model of $140 \mathrm{~km} \times 160 \mathrm{~km}$ with strike and dip angles of our fault model are $\mathrm{N} 246^{\circ} \mathrm{E}$ and $18^{\circ}$, respectively, placed on the estimated upper boundary of the subducting Pacific Plate. The estimated total slip distribution consisted of three major slip areas; (a) around the hypocenter, (b) the northwest part of the fault with the maximum slip of $5.9 \mathrm{~m}$, and (c) the northeast edge of the fault plane. The major asperity (b) was composed of two large slip areas with different slip rate functions: the duration of moment release in the sourtheast part is longer than $15 \mathrm{sec}$, but in contrast most of the seismic moment of the northwest part was released in a short period of less than $10 \mathrm{sec}$. Our estimation of the total seismic moment was $2.9 \times 10^{21} \mathrm{~N} \cdot \mathrm{m}$ which corresponded to $\mathrm{Mw}=8.2$.
\end{abstract}

Key words: 2003 Tokachi-oki earthquake, rupture process, strong motion, K-NET, KiK-net.

\section{Introduction}

On 26th September 2003 at 4:50 (JST), the Tokachi-oki earthquake $\left(\mathrm{M}_{J M A}\right.$ 8.0) struck the northern Japanese island of Hokkaido. A number of large interplate earthquakes have occurred along the Northern Japan Trench and Southern Kuril Trench off Hokkaido. A previous Tokachi-oki event in the same source region as that of the 2003 event occurred on 4 March 1952. The epicenter of the 2003 event was very close to that of the 1952 event (Fig. 1). The mechanism of the 2003 event was estimated to be of the thrust type by Hinet (High-sensitivity seismograph network; Obara, 2002) or F-net (Full range seismograph network of Japan; Fukuyama et al., 1996) (Fig. 2).

Previous studies have provided information about the characteristics of the 1952 event. The size of the fault plane estimated from leveling data by Kasahara (1975) was 100 $\mathrm{km} \times 70 \mathrm{~km}$ and the source region, as estimated from the tsunami travel times (Hatori, 1973) was almost identical with that estimated by Kasahara. Yamanaka and Kikuchi (2002) proposed an asperity distribution from a waveform inversion analysis using JMA (Japan Meteorological Agency) strong motion records from three stations. Hirata et al. (2003) assumed 10 subfaults on the subducting plate and estimated the slip distribution on each subfault by an inversion analysis using tsunami waveforms. These previous studies show us only the overall features of the 1952 earthquake such as the size

Copy right(c) The Society of Geomagnetism and Earth, Planetary and Space Science (SGEPSS); The Seismological Society of Japan; The Volcanological Society of Japan; The Geodetic Society of Japan; The Japanese Society for Planetary Sciences; TERRAPUB of the fault plane and location of the major asperity, because the observations were of insufficient quality and quantity.

The 2003 Tokachi-oki earthquake was the first large interplate earthquake recorded by the nationwide strong motion networks, K-NET (Kinoshita, 1998) and KiK-net (Aoi et al., 2000). The networks were established after the 1995 Hyogoken-Nanbu earthquake, and the average station-tostation distance is about $20 \mathrm{~km}$. The strong motion accelerometers of K-NET are installed on the surface, and those of KiK-net are installed both at the bottoms of boreholes together with Hi-net seismographs and on the surface. Each station has a digital strong motion seismograph with a wide frequency band and wide dynamic range, having a maximum measurable acceleration of $2000 \mathrm{~cm} / \mathrm{s}^{2}$.

Here, we review the strong motions observed by K-NET and KiK-net during the 2003 Tokachi-oki earthquake and estimate the rupture process by the waveform inversion analysis of the strong-motion records.

\section{Strong Motion Observation}

Most of the acceleration records from the 655 stations (K-NET and KiK-net) were collected within 5 h by dialup operation from the data management center of NIED (National Research Institute for Earth Science and Disaster Prevention). The maximum peak acceleration of 988 $\mathrm{cm} / \mathrm{s}^{2}$, obtained by vector summation of the three components, recorded at station HKD100 (K-NET) which is shown in Fig. 1.

Figure 3 compares the observed peak ground acceleration (PGA) and velocity (PGV) by an empirical attenuation rela- 


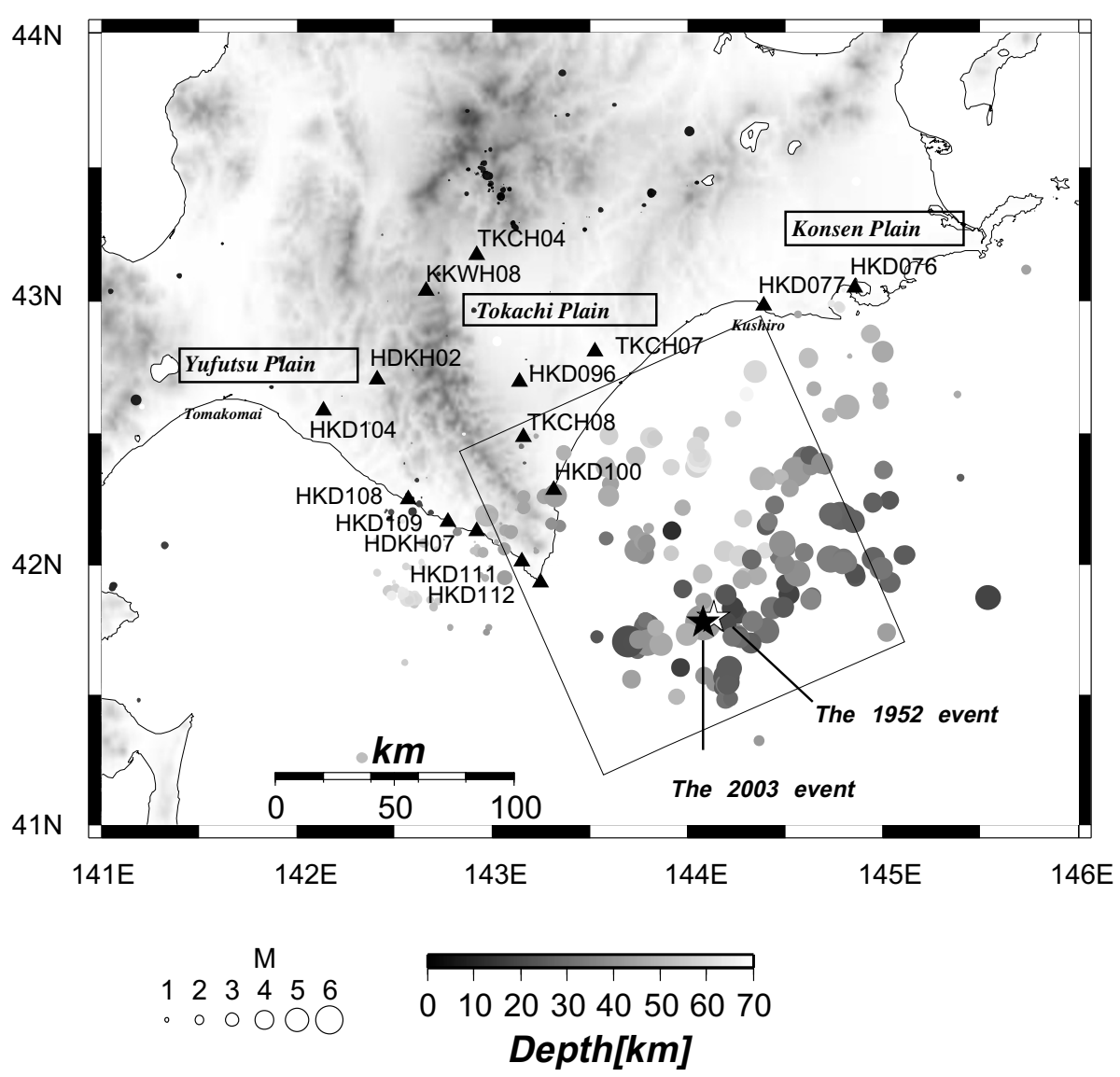

Fig. 1. Stations which are used for the inversion and aftershock distributions over two days (26 and 27 September) selected from the JMA unified catalog. The rectangle represents assumed fault plane.
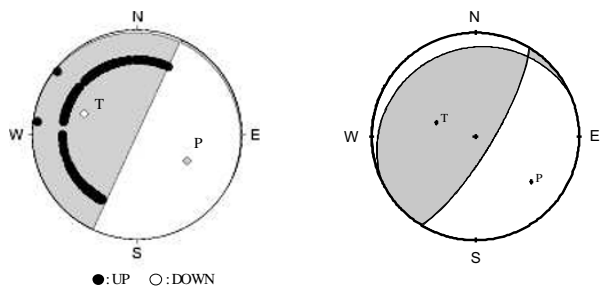

Fig. 2. Two fault mechanisms estimated (left) by distribution of polarity of the $P$-wave by Hi-net and (right) by moment tensor analysis of F-net data (Matsubayashi, personal communication).
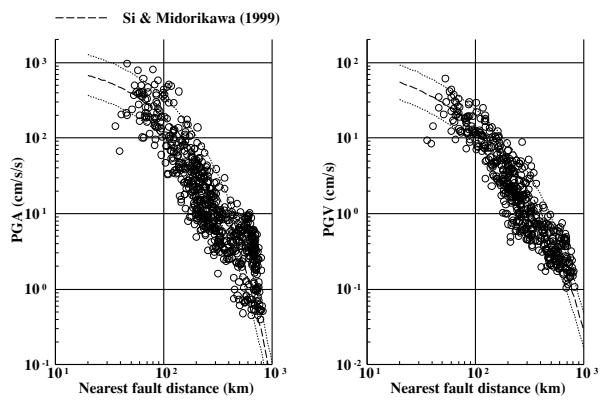

Fig. 3. Comparison between observed peak ground motions and an empirical attenuation relationship (dashed lines). Left: PGA at the surface. Right: PGV on the engineering bedrock $(V s=600 \mathrm{~m} / \mathrm{s})$, corrected in accordance with the method of Si and Midorikawa (1999). Dotted lines indicate the standard deviations of the empirical relationships.
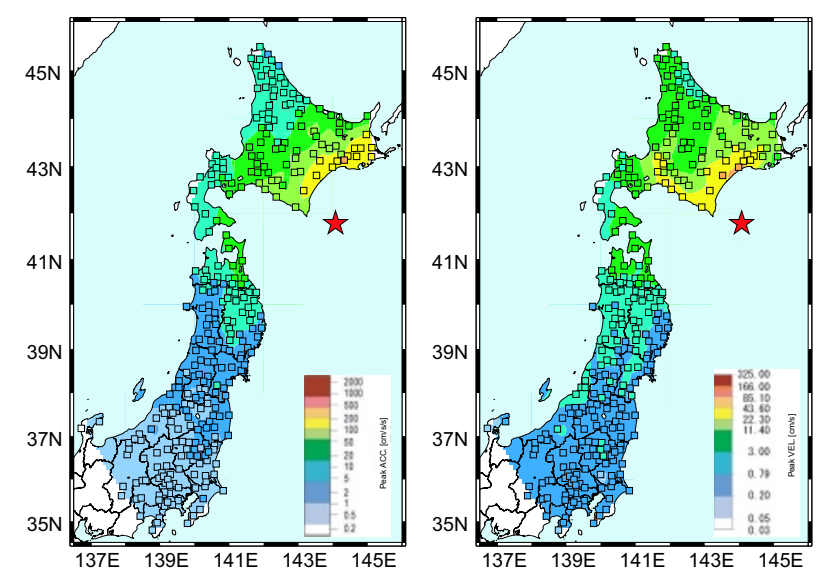

Fig. 4. Under ground peak acceleration (left) and velocity (right) distributions recorded by KiK-net.

tionship proposed by Si and Midorikawa (1999). Observed PGVs were corrected to values on the engineering bedrock in accordance with the method of Si and Midorikawa (1999). They defined the engineering bedrock as stiff rock whose $S$ wave velocity is larger than $600 \mathrm{~m} / \mathrm{s}$. As shown in Fig. 3, attenuations of peak ground motion were in good agreement with the empirical attenuation relationship for the 2003 Tokachi-oki earthquake for up to $800 \mathrm{~km}$.

The distributions of observed peak ground motions at the bottoms of the boreholes (Fig. 4) and on the surface (Fig. 5) 

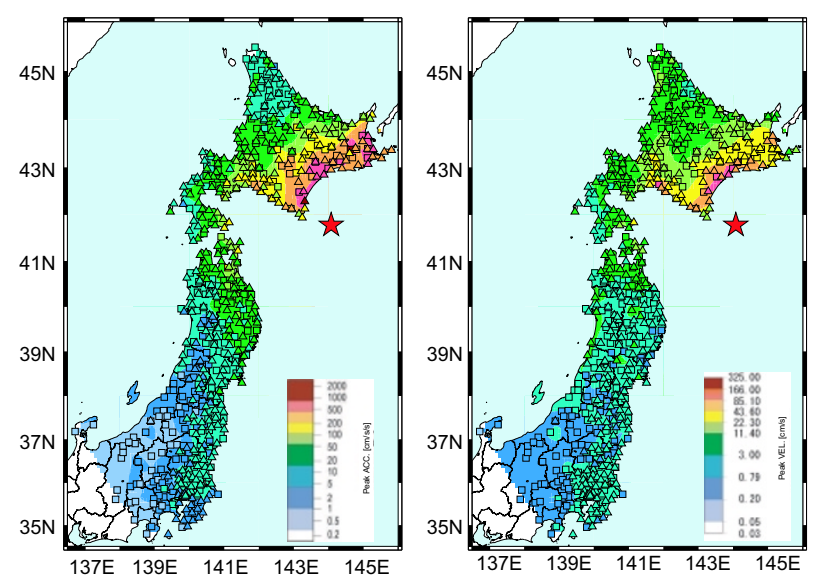

Fig. 5. Surface peak acceleration (left) and velocity (right) distributions recorded by K-NET and KiK-net. The star shows the epicenter.

showed that the ground motions on the surface were much larger than those at the bottoms of boreholes. Because most boreholes of KiK-net stations in Hokkaido are at depth of 100 to $200 \mathrm{~m}$ and do not reach to the basement rock, differences in ground motions between the surface and the bottoms of boreholes appeared in the high frequency range. Therefore amplification of PGA was more remarkable than that of PGV.

\section{Rupture Process of the $\mathbf{2 0 0 3}$ Tokachi-oki Earth- quake}

\subsection{Finite fault model}

A fault plane model was assumed as follows;

(1) The epicenter was determined from the JMA unified hypocenter catalog (lat $41.7797 \mathrm{~N}$, long $144.0795 \mathrm{E}$ ).

(2) The size of the fault area was inferred from the aftershock distributions (140 km long and $160 \mathrm{~km}$ wide).

(3) The strike $\left(246^{\circ}\right)$ and rake angles $\left(127^{\circ}\right)$ were determined from a moment tensor solution from F-net records (Matsubayashi, personal communication).

(4) The dip angle $\left(18^{\circ}\right)$ and the focal depth $(29 \mathrm{~km})$ corresponded to those of the subducting plate.

Because this earthquake occurred on the interface of the subducting plate, away from inland stations, the station coverage was not ideal and we had difficulty locating from only the direct waves recorded at the inland stations. Therefore, we used the epicenter in JMA unified catalog determined together with inland stations and OBS (Ocean-Bottom Seismometers) installed at off-Kushiro.

Figure 1 is a map of the source region showing the distribution of aftershocks on 26 and 27 September and station locations used for the inversion analysis. The aftershock distribution and the focal mechanism of the main shock (Fig. 2) suggest that this event was an interplate earthquake due to thrust faulting between the subducting Pacific Plate and the overriding North American Plate.

The aftershock distributions were inclined to the northwest with a dip angle of $18^{\circ}$ along the plate boundary. JMA
Table 1. Velocity structure used in this study.

\begin{tabular}{rccc}
\hline Depth $(\mathrm{m})$ & $V p(\mathrm{~m} / \mathrm{s})$ & $V s(\mathrm{~m} / \mathrm{s})$ & Density $\left(\mathrm{kg} / \mathrm{m}^{3}\right)$ \\
\hline 0 & 6000 & 3550 & 2700 \\
4500 & 6200 & 3668 & 2770 \\
9000 & 6500 & 3846 & 2800 \\
19000 & 6600 & 3851 & 2830 \\
28000 & 6700 & 3861 & 2860 \\
28500 & 7000 & 4002 & 2900 \\
29000 & 7300 & 4200 & 3100 \\
29500 & 7600 & 4370 & 3150 \\
30000 & 7800 & 4483 & 3200 \\
40000 & 7900 & 4488 & 3250 \\
50000 & 8000 & 4520 & 3270 \\
60000 & 8100 & 4576 & 3290 \\
70000 & 8200 & 4632 & 3310 \\
\hline
\end{tabular}

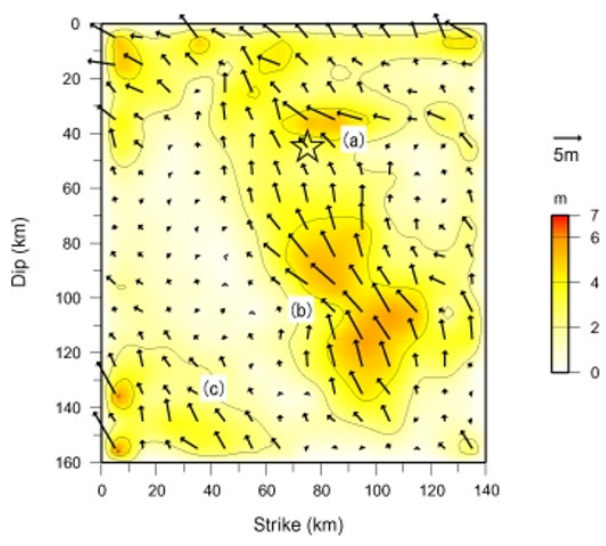

Fig. 6. Estimated total slip distribution. Star indicates the hypocenter. Arrows show the amplitudes and directions of slip.

determined the hypocenter depth as $42 \mathrm{~km}$, but this seemed deeper than the depth of the plate boundary as inferred from the aftershock distribution (Fig. 1). Therefore, we use a depth of $29 \mathrm{~km}$ so that the hypocenter fell on the plate boundary; this depth agreed with that determined by F-net.

\subsection{Data and method}

For the analysis, we used strong motion data from $15 \mathrm{~K}$ NET and KiK-net stations whose epicentral distances were all within $200 \mathrm{~km}$. Their locations were shown in Fig. 1. The observed acceleration records were integrated into velocity and bandpass filtered between 0.02 and $0.2 \mathrm{~Hz}$. We inverted $85 \mathrm{~s}$ of the $S$-wave portion from $5 \mathrm{~s}$ before the $S$ wave arrivals. Obscure onset of body waves are observed at many stations. In particular, $S$-wave arrivals were hard to determine because they were contaminated by the later phases of the $P$-wave. We used the theoretical $S$ - $P$ time for our assumed velocity structure to infer which phase was the direct $S$-wave.

Theoretical Green's functions were calculated by the discrete wavenumber method (Bouchon, 1981) and the $R / T$ matrix method (Kennett, 1983) with the stratified medium shown in Table 1 (Iwasaki et al., 1991). Convolution of moving dislocation was introduced to represent the rupture propagation in a each subfault (Sekiguchi et al., 2002).

We use the multi-time-window linear waveform inversion procedure (Hartzell and Heaton, 1983), in which the 


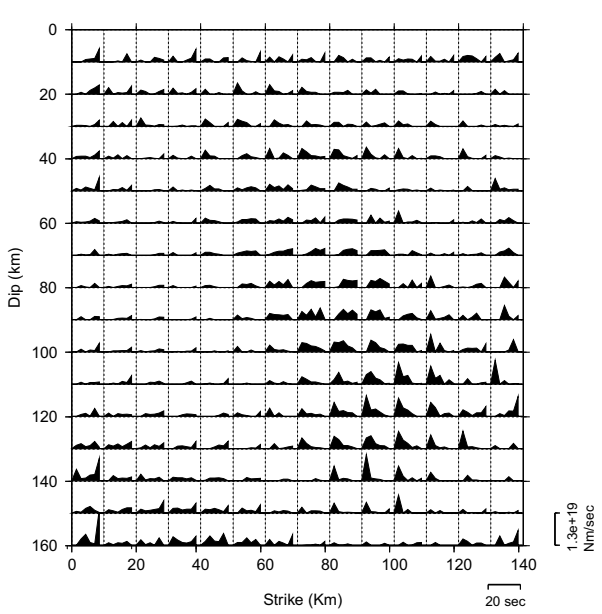

Fig. 7. Source time functions in each subfault.

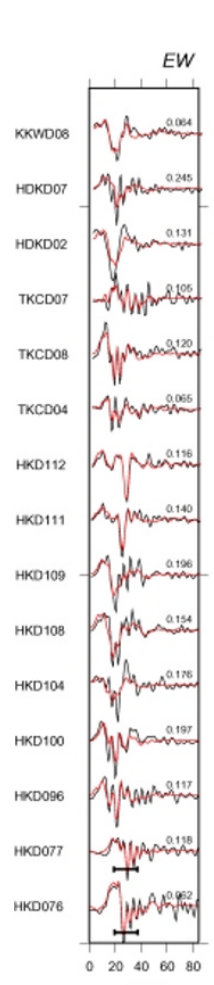

sec

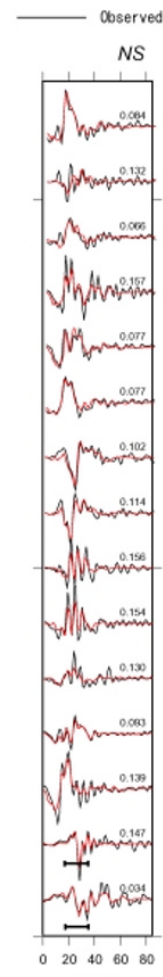

$\sec$

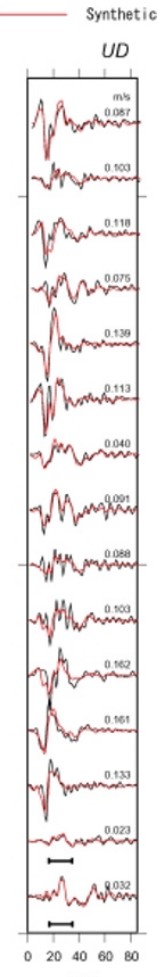

$\sec$
Fig. 8. Comparison between observed and synthesized velocity waveforms. The maximum values of each component are given to the right of each trace in $\mathrm{m} / \mathrm{s}$. Each trace is normalized by the maximum amplitude recorded at each station.

moment-release distribution is discretized in both space and time. Discretization in space is done by dividing the model fault planes into 224 subfaults, each $10 \mathrm{~km} \times 10 \mathrm{~km}$. We assumed 6 triangles with $5 \mathrm{sec}$ duration separated by 2.5 sec to represent the discretized time window on each subfault. Although we assume a constant rupture velocity for the triggering of the first time window, multiple time window analysis allowed variable rupture velocity and slip duration as functions of fault position. To reduce instability or excessive complexity, smoothing constraint that reduce differences among slips close in space and in time is introduced. Non-negative constraints (Lawson and Hanson,

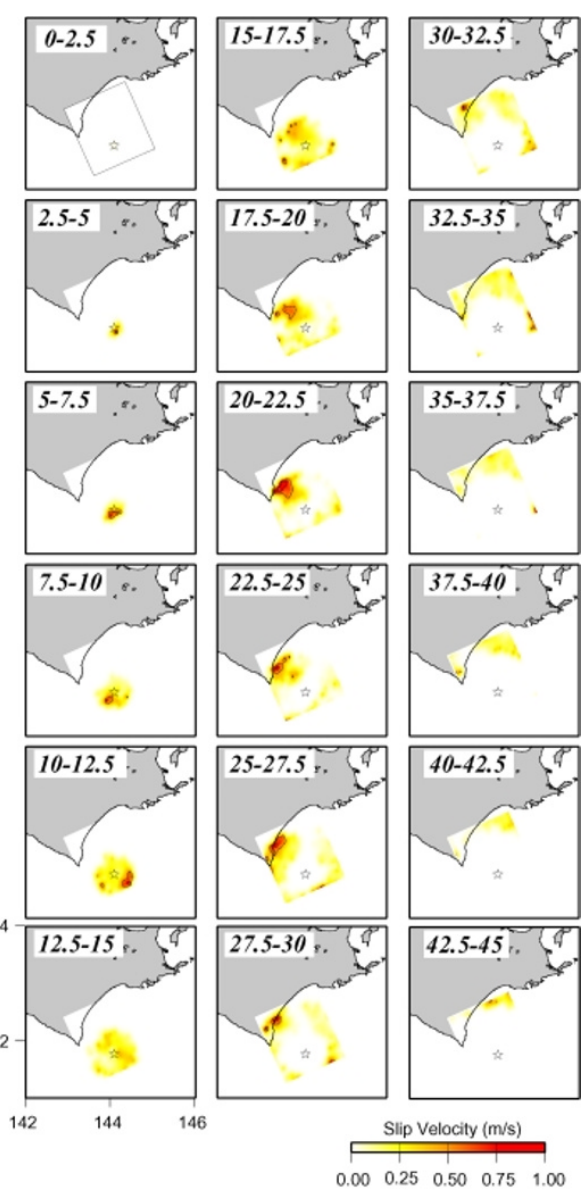

Fig. 9. Time progression of the rupture propagation. Contour interval of slip velocity is $0.25 \mathrm{~m} / \mathrm{s}$ with a range of 0.5 to $1.0 \mathrm{~m} / \mathrm{s}$. Star indicates the hypocenter.

1974) to limit the rake-angle variation are also adopted. The rake angles were allowed to vary within $\pm 45^{\circ}$ centered at $127^{\circ}$ which is the moment tensor solution of F-net. We performed many inversions changing the rupture velocity of the first time windows and the smoothing strength. Appropriate values for the smoothing strength and the rupture velocity were selected based on ABIC (Akaike's Bayesian Information Criterion; Akaike, 1980) and the residual of the waveform fitting, respectively.

\subsection{Inversion results}

Figure 6 shows the estimated total slip distribution, which consisted of three notable slip areas; (a) around the hypocenter, (b) the northwest part of the fault with the maximum slip of $5.9 \mathrm{~m}$, and (c) the northeast edge of the fault plane. The slips near the shallower margin of the fault plane were expected not to be constrained well, because the stations covered only the northwest side of the fault plane. The estimated total seismic moment was $2.9 \times 10^{21} \mathrm{~N} \cdot \mathrm{m}$.

Figure 7 shows the source-time functions at each subfault. The largest asperity seemed to be divided into two parts. The amounts of slip in the two parts were comparable, however, the manners of moment release were quite different. The duration of moment release from the subfaults in the southeast part was longer than $15 \mathrm{~s}$. In contrast, most of the moment from subfaults in the northwest part was released over a short period less then $10 \mathrm{~s}$. 
Table 2. Variation in estimated seismic moment (Mo) and moment magnitude (Mw). The bottom three results are moment tensor solutions. The others are deduced from slip distributions on assumed fault planes.

\begin{tabular}{lccc}
\hline & Mw & Mo $\left(10^{21} \mathrm{~N} \cdot \mathrm{m}\right)$ & data \\
\hline This study & 8.2 & 2.9 & Strong motion records \\
Koketsu et al. (2004) & 8.2 & 2.2 & Strong motion records, GPS \\
Yagi (2004) & 8.1 & 1.7 & Teleseismic body wave, strong motion records \\
Yamanaka and Kikuchi (2003) & 8.0 & 1.0 & Teleseismic body wave \\
Harvard CMT catalog & 8.3 & 3.5 & Mantle wave \\
USGS fast moment tensor solution & 8.1 & 1.6 & Teleseismic body wave \\
F-net & 7.9 & 0.8 & Surface wave \\
\hline
\end{tabular}

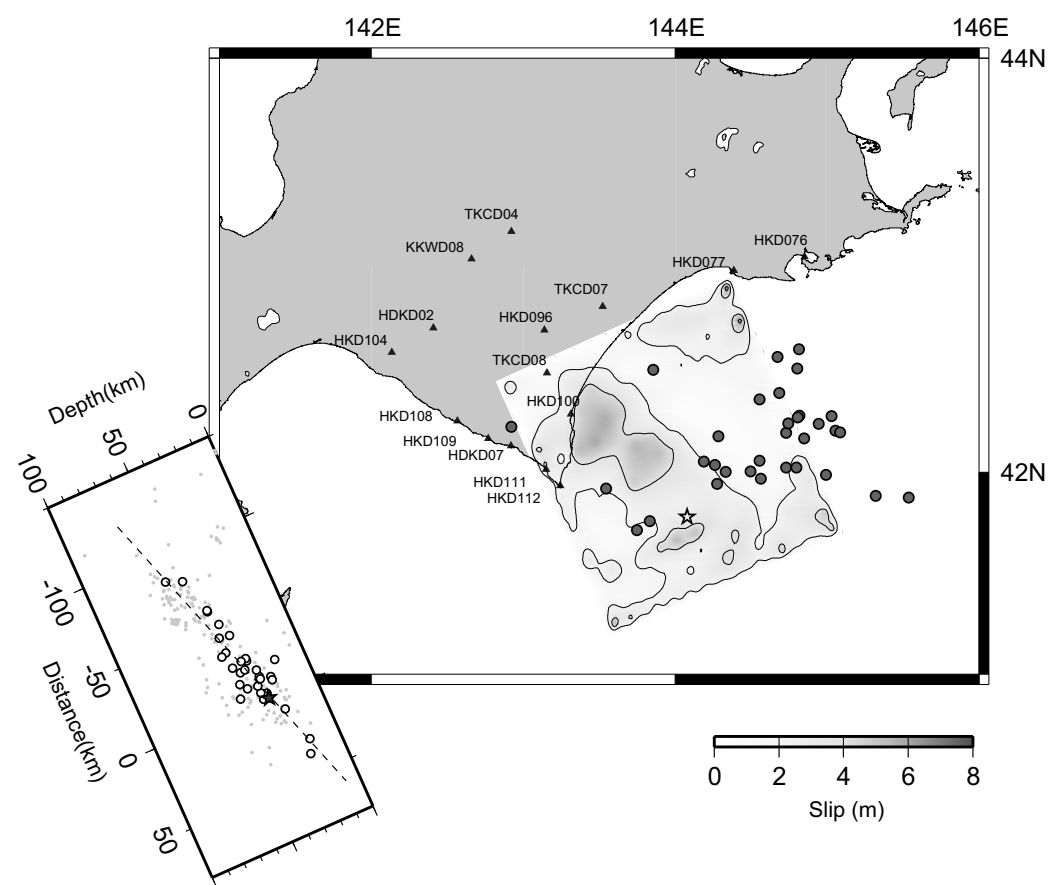

Fig. 10. Estimated total slip distribution and thrust type aftershocks, as determined by Ito et al. (2004). The vertical cross section along the dip direction is shown at left. Dotted line shows the dip angle of the fault plane.

Figure 8 compares the observed seismograms (solid lines) with synthetics for the estimated rupture process (dotted lines). The overall waveform matching was good at all stations. Solid bars under the seismograms recorded at stations HKD076 and HKD077 indicated phases from an asperity (c).

The time progression of the rupture is given in Fig. 9. The propagation velocity of the first-time-window triggering was $3500 \mathrm{~m} / \mathrm{s}$. The major rupture initially propagated in almost a down-dip direction, from (a) to (b), and about $20 \mathrm{~s}$ later the direction rotated westward.

\section{Discussions and Conclusions}

The 2003 Tokachi-oki earthquake was the largest interplate earthquake ever since K-NET and KiK-net were established. The overall features of observed the PGA and PGV can be explained by empirical attenuation relationships. The ground motions due to the event were observed over a wide region and the rupture process was deduced from the strong motions observed at the $15 \mathrm{~K}$-NET and KiK-net stations. The largest slip $(5.9 \mathrm{~m})$ occurred beneath the east coast of the Cape Erimo. The total seismic moment estimated in this study $2.9 \times 10^{21} \mathrm{~N} \cdot \mathrm{m}$, was in between those of the Harvard CMT catalog $\left(3.5 \times 10^{21} \mathrm{~N} \cdot \mathrm{m}\right)$ and the USGS fast moment tensor solution $\left(1.6 \times 10^{21} \mathrm{~N} \cdot \mathrm{m}\right)$, obtained by using longperiod waves. The other results obtained by various data and methods are approximately match our results (see Table 2 ).

Oil tanks at Tomakomai, located in the extended direction of propagation of the major ruptures propagation direction were seriously damaged by sloshing caused by the longperiod waves, which for a long time. The main cause of this phenomenon was the large plane structure with a very thick sediment. The directivity effect of the largest asperity might have increased the amplitude of the wave incident to the plane.

PGVs larger than $40 \mathrm{~cm} / \mathrm{s}$ (Fig. 5) were also recorded in eastern Hokkaido, where the forward directivity effect of the largest asperity ((b) in Fig. 6) on the strong motions was less effective. Contribution of waves from the small asperity ((c) in Fig. 6) to the largest phases at stations HKD076 and HKD077, indicated by the solid bars in Fig. 8, is essential if we are to explain the amplitudes. A source model obtained by the empirical Green's function method also supposes the existence of asperity (c) (Morikawa et al., 2004).

Hirata et al. (2003) analyzed 13 tsunami waveforms recorded in northern Japan and retrieved the slip distributions on 10 subfaults whose smallest size is $47 \mathrm{~km} \times 45 \mathrm{~km}$. 
They concluded that the largest stress drop of the previous event occurred at east of Cape Erimo in the previous event. In comparing their results with ours, we can say that the location of the largest asperity was almost identical, within the resolution of their analysis.

Figure 10 shows the distributions of thrust-type aftershocks, whose Mw were larger than 4, as relocated by Ito et al. (2004), together with the slip distribution of the main shock. The aftershocks distribution seemed to be anticorrelated with the large slip areas of the main shock. The aftershocks occurred outside the region of the large coseismic slip. Some previous studies have pointed out similar phenomena (e.g., Mendoza and Hartzell, 1988; Wald et al., 1990). These results may imply that the relationship between the coseismic slip and the aftershocks can be interpreted as resulting from a redistribution of stress following coseismic slip on the fault plane.

Acknowledgments. We would like to thank to Mr. Matsubayashi. He kindly provided his moment tensor solution for us. We are also grateful to Mr. Ito, Dr. Hayashi and Dr. Asano for valuable discussions. We appreciate to Dr. Katsumata for his valuable advice. We thank to Dr. Furumura and Dr. Kato. They reviewed our manuscript and gave advice on improving it. GMT (Wessel and Smith, 1995) was used to make the figures. This work was conducted under the auspices of the "National Strong Motion Mapping Project" of the National Research Institute for Earth Science and Disaster Prevention, Japan.

\section{References}

Akaike, H., Likelihood and the Bayes procedure, in Bayesian statics, edited by, J. M. Bernardo, M. H. DeGroot, D. V. Lindley, and A. F. M. Smith, University Press, Valencia, Spain, 1980.

Aoi, S., K. Obara, S. Hori, K. Kasahara, and Y. Okada, New strong-motion observation network: KiK-net, EOS. Trans. Am. Geophys. Union, 329, 2000 .

Bouchon, M., A simple method to calculate Green's function for elastic layered media, Bull. Seism. Soc. Am., 71, 959-971, 1981.

Fukuyama, E., M. Ishida, S. Hori, S. Sekiguchi, and S. Watada, Broadband seismic observation conducted under the FREESIA Project, Rep. Nat'l. Res. Inst. Earth Sci. Disas. Prev., 57, 23-31, 1996.

Hartzell, S. H. and T. Heaton, Inversion of strong ground motion and teleseismic waveform data for the fault rupture history of the 1979 Imperial Valley, California, earthquake, Bull. Seism. Soc. Am., 73, 1553-1583, 1983.

Hatori, T., Reexamination of the wave source of the 1952 Tokachi-Oki tsunami, J. Seismol. Soc. Jpn., 26, 206-208, 1973 (in Japanese with English abstract and figure captions).

Hirata, K., E. Geist, K. Satake, Y. Tanioka, and S. Yamaki, Slip distribution of the 1952 Tokachi-Oki earthquake (M 8.1) along the Kuril
Trench deduced from tsunami waveform inversion, J. Geophys. Res., 198 doi:10.1029/2002JB001976, 2003

Ito, Y., H. Matsubayashi, H. Kimura, T. Matsumoto, Y. Asano, and S. Sekiguchi, Spatial distribution for moment tensor solutions of the 2003 Tokachi-oki earthquake ( $\mathrm{Mw}=7.9)$ and aftershocks, Earth Planets Space, 56, this issue, 301-306, 2004.

Iwasaki, T., N. Hirata, T. Kanazawa, T. Urabe, Y. Motoya, and H. Shimamura, Earthquake distribution in the subduction zone off eastern Hokkaido, Japan, deduced from ocean-bottom seismographic and land observations, Geophys. J. Int., 105, 693-711, 1991.

Kasahara, M., A fault model of the Tokachi-Oki earthquake of 1952, Seismol. Soc. Jpn. Program Abstr., 90, 1975 (in Japanese).

Kennett, B. L. N., Seismic wave propagation in stratified media, Cambridge University Press., Cambridge, 1983.

Kinoshita, S., Kyoshin net (k-net), Seism. Res. Lett., 69, 309-332, 1998.

Koketsu, K., K. Hikima, S. Miyazaki, and S. Ide, Joint inversion of strong motion and geodetic data for the source process of the 2003 Tokachioki, Hokkaido, earthquake, Earth Planets Space, 56, this issue, 329-334, 2004

Lawson, C. and R. Hanson, Solving Least Squares Problems, Prentice-Hall, Inc., New Jersey, 1974

Mendoza, C. and S. Hartzell, Aftershock patterns and main shock faulting, Bull. Seism. Soc. Am., 78, 1438-1449, 1988.

Morikawa, N., S. Aoi, R. Honda, and H. Fujiwara, Characterized source model of the 2003 Tokachi-oki earthquake for broadband strong ground motion evaluation, The 2004 Japan Earth and Planetary Science Joint Meeting, Chiba, Japan, 2004

Obara, K., Hi-net: High sensitivity seismograph network, Japan, Lecture Note in Earth Sciences, 98, 79-87, 2002.

Sekiguchi, H., K. Irikura, and T. Iwata, Source inversion for estimating continuous slip distribution on the fault-Introduction of Green's functions convolved with a correction function to give moving dislocation effects in subfaults-, Geophys. J. Int., 150, 377-391, 2002.

$\mathrm{Si}, \mathrm{H}$. and S. Midorikawa, New attenuation relationships for peak ground acceleration and velocity considering effect of fault type and site condition, J. Struct. Constr. Eng., 523, 63-70, 1999 (in Japanese with English abstract and figure captions).

Wald, D. J., D. Helmberger, and S. Heartzell, Rupture process of the 1987 Superstition Hills earthquake from the inversion of strong-motion data, Bull. Seism. Soc. Am., 80, 1079-1098, 1990.

Wessel, P. and W. Smith, New version of the generic mapping tools, EOS Trans. Am. Geophys. Un., 76, 329,1995.

Yagi, Y., Source rupture process of the 2003 Tokachi-oki earthquake determined by joint inversion of teleseismic body wave and strong ground motion data, Earth Planets Space, 56, this issue, 311-316, 2004.

Yamanaka, Y. and M. Kikuchi, Asperity map along the subduction zone in Hokkaido region inferred from historical seismograms, Seismol. Soc. Jpn. Programme. Abstr. Fall Meeting, 2002.

Yamanaka, Y. and M. Kikuchi, Source process of the recurrent Tokachi-oki earthquake on September 26, 2003, inferred from telesesmic body waves, Earth Planets Space, 55, e21-e24, 2003.

R. Honda, S. Aoi (e-mail: aoi@bosai.go.jp), N. Morikawa, H. Sekiguchi, T. Kunugi and H. Fujiwara 